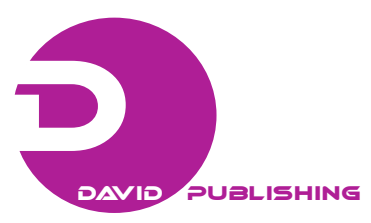

\title{
Safety Analysis for Older Drivers at Signalized Intersections
}

\author{
Daba S. Gedafa \\ Department of Civil Engineering, University of North Dakota, Grand Forks ND 58202-8115, USA
}

\begin{abstract}
The proportions of older drivers continue to increase since baby boom generation is becoming old. The level of mobility of older drivers is also increasing. Older drivers begin to noticeably be over-involved in fatal crashes. Intersections appear to be hazardous to older drivers, particularly left turn due to one or more of: sensory, perceptual, cognitive, physical and general driving knowledge deficiencies. The safety concern of older drivers is also becoming significant. Ten years of crash data has been extracted from Kansas accident report system. It has been analyzed using SAS (statistical analysis system) software. Five different age groups have been considered. Comparison has been made between different age groups of the same gender, and the same age group for different gender. Effects of light condition, weather condition, surface type, surface condition, road character and construction/maintenance zone on older drivers' safety have also been considered in this study. It has been found out that proportion of older drivers in through movement involved in accident decreases as age increases whereas the proportion of left turn accidents increases with age, left turn is harder for females in all age groups, and proportion of right turn accidents has no specific trend. Most of the accidents have taken place during daylight when there are no adverse weather conditions on dry surface, straight and level road, and blacktop surface type.
\end{abstract}

Key words: Traffic safety, older drivers, intersections.

\section{Introduction}

The proportions of older drivers continue to increase since baby boom generation is becoming old $[1,2]$. The level of mobility of older drivers is also increasing [3]. Older drivers are the fastest growing segment of the driving population [4]. In 2000, the elderly accounted for $12.4 \%$ of the U.S. population. It is estimated that persons who are 65 years old and over will make up more than $15 \%$ of the total drivers [5], the number will approximately be 50 million in 2020 [6] and 20\% of the total drivers in 2030 [7]. According to FHWA (Federal Highway Administration), if design is controlled by 85th percentile performance requirements, individual over 65 years old will be the design driver in the early 21st century [8].

Corresponding author: Daba S. Gedafa, Ph.D., P.E., assistant professor, research fields: mechanistic-empirical design, pavement management system, non-destructive testing, materials engineering and traffic safety. E-mail: daba.gedafa@engr.und.edu.
Older drivers begin to noticeably be over-involved in fatal crashes. In the next 30 years, due to the increased number of older drivers, the number of fatalities involving older drivers is expected to increase three to four times if there is no change in the current crash rates [7,9]. Some of the factors for higher fatality rates are related to body frailty and environmental factors [10-13]. The higher crash propensity of older drivers is often attributed to typical aging-related deterioration [14-16]. A recent written report identified five main deficiencies present in older drivers. These include: sensory, perceptual, cognitive, physical and general driving knowledge deficiencies [17].

Intersections appear to be hazardous to elderly drivers [1, 18], particularly left turn. Studies have indicated that a large majority of accidents involving elderly drivers take place at intersections. The main difficulties elderly drivers face at intersections are: estimation of a safe gap and speed of other vehicles, 
fast execution of driving maneuvers, failure to sense and comprehend traffic signals and signs, inability to perceive and process information about high traffic volumes, failure to signal their turns, poor positioning when turning left along with a general lack of caution, frequent failure to stop, and jerky or abrupt stops [2, 9].

The safety concern of older drivers is becoming significant. In this study, ten years crash data at signalized intersections in Kansas has been analyzed and comparison has been made for drivers in five different age groups for men and women. Different severity levels have been considered separately and finally, overall crash data has been analyzed for through, left turn and right turn movements.

\section{Objectives}

The main objectives of this study are:

(1) Analyze crash data at signalized intersections in Kansas for older drivers;

(2) Compare the result within the same age group and different gender and different age group of the same gender; and

(3) Determine the effect of light condition, weather condition, surface type, surface condition, road character and construction/maintenance zone on the safety of older drivers.

\section{Data and Methodology}

Ten years of crash data, 1993-2002, have been extracted from Kansas accident report system data base for drivers older than 29 years. TH (Through), RT (right turn) and LT (left turn) crashes have been considered separately. The various injury severities are considered: D (disabled-incapacitating), F (fatal injury), I (injury-not incapacitating), N (not injured) and $\mathrm{P}$ (possible injury).

Many researchers commonly classify the elderly population into three subgroups as younger old: ages 65-74, older old: ages 75-84 and oldest old: ages over 85 [19]. In another study, drivers from ages 30 to 50 as middle-aged, ages 65 to 74 as young elderly, over
Table 1 Five age groups for this study.

\begin{tabular}{lll}
\hline Serial number & Age group & Remark \\
\hline 1 & $30-49$ & Comparison group \\
2 & $50-64$ & \\
3 & $65-74$ & \\
4 & $75-84$ & \\
5 & $>85$ & \\
\hline
\end{tabular}

75 as old elderly [1]. Five age groups have been considered in this study as shown in Table 1.

SAS (statistical analysis software) has been used to analyze the data in this study. Then comparison has been made for different age groups of the same gender and the same age group for different gender.

\section{Results and Discussions}

\subsection{Linear Regression}

Intercept, slope, and coefficient of determination $\left(R^{2}\right)$ have been determined by using SAS based on age group as independent variable and severity level as dependent variable. The results are shown in Table 2 . The higher the coefficient of determination, the better the linear model compared to intercept only model. T-test has been done to determine the significance of the intercepts and slopes at 5\% significance level. The slopes and intercepts that are not significant are indicated by * in the table. If slope is not significant, there is no linear relationship between severity level and age group. The intercepts for TH are higher for males than that of females at all age groups as shown in Fig. 1. The slope shows a decrease in proportion of $\mathrm{TH}$ accident for a unit increase in age group. The magnitude of slopes for females are higher than that of males in disabled and possible injury cases whereas higher for males in fatal, injury (not incapacitated), and not injured cases. As a result, there is no specific trend in slope unlike the intercept.

Table 2 also shows the linear model coefficients for LT accidents. Unlike that of $\mathrm{TH}$ accident, the intercepts for females are higher than that of males. The slopes for males are higher than that of females except in disabled case. Both the slope and intercept 
Table 2 Summary statistics of linear models for various severity levels.

\begin{tabular}{|c|c|c|c|c|c|c|c|}
\hline \multirow{3}{*}{ Severity } & \multirow{3}{*}{ Statistics } & \multicolumn{6}{|c|}{ Sex } \\
\hline & & \multicolumn{3}{|c|}{ Female } & \multicolumn{3}{|c|}{ Male } \\
\hline & & $\mathrm{TH}$ & $\mathrm{LT}$ & RT & $\mathrm{TH}$ & $\mathrm{LT}$ & $\mathrm{RT}$ \\
\hline \multirow{3}{*}{ D } & Intercept & 97.20 & 1.80 & $1.00 *$ & 101.36 & $-2.64 *$ & $1.28 *$ \\
\hline & Slope & -6.96 & 6.55 & $0.41 *$ & -5.27 & 5.46 & $-0.19 *$ \\
\hline & $R^{2}$ & 0.93 & 0.94 & $0.62 *$ & 0.94 & 0.96 & $0.24 *$ \\
\hline \multirow{3}{*}{$F$} & Intercept & 86.24 & $12.38^{*}$ & $1.38 *$ & 105.59 & $-5.68 *$ & $0.07 *$ \\
\hline & Slope & $-0.78 *$ & $1.04 *$ & $-0.26^{*}$ & -6.23 & 6.01 & $0.23 *$ \\
\hline & $R^{2}$ & $0.02 *$ & $0.04 *$ & $0.25 *$ & 0.94 & 0.97 & $0.28 *$ \\
\hline \multirow{3}{*}{ I } & Intercept & 91.13 & $7.47^{*}$ & 1.40 & 96.60 & $1.10^{*}$ & 2.30 \\
\hline & Slope & -4.84 & 4.51 & 0.34 & -5.09 & 5.10 & $-0.01 *$ \\
\hline & $R^{2}$ & 0.78 & 0.75 & 0.89 & 0.79 & 0.79 & $0.01 *$ \\
\hline \multirow{3}{*}{$N$} & Intercept & 87.06 & 9.34 & 3.60 & 89.86 & 5.80 & 4.35 \\
\hline & Slope & -4.53 & 3.73 & 0.80 & -4.98 & 4.39 & 0.59 \\
\hline & $R^{2}$ & 0.93 & 0.92 & 0.95 & 0.98 & 0.98 & 0.88 \\
\hline \multirow{3}{*}{$P$} & Intercept & 88.04 & 10.36 & $1.60^{*}$ & 91.79 & $5.32 *$ & 2.89 \\
\hline & Slope & -4.49 & 3.81 & $0.68 *$ & -4.05 & 3.93 & $0.12^{*}$ \\
\hline & $R^{2}$ & 0.98 & 0.95 & $0.55^{*}$ & 0.94 & 0.95 & $0.08^{*}$ \\
\hline
\end{tabular}

* Not significant at $5 \%$ significance level.

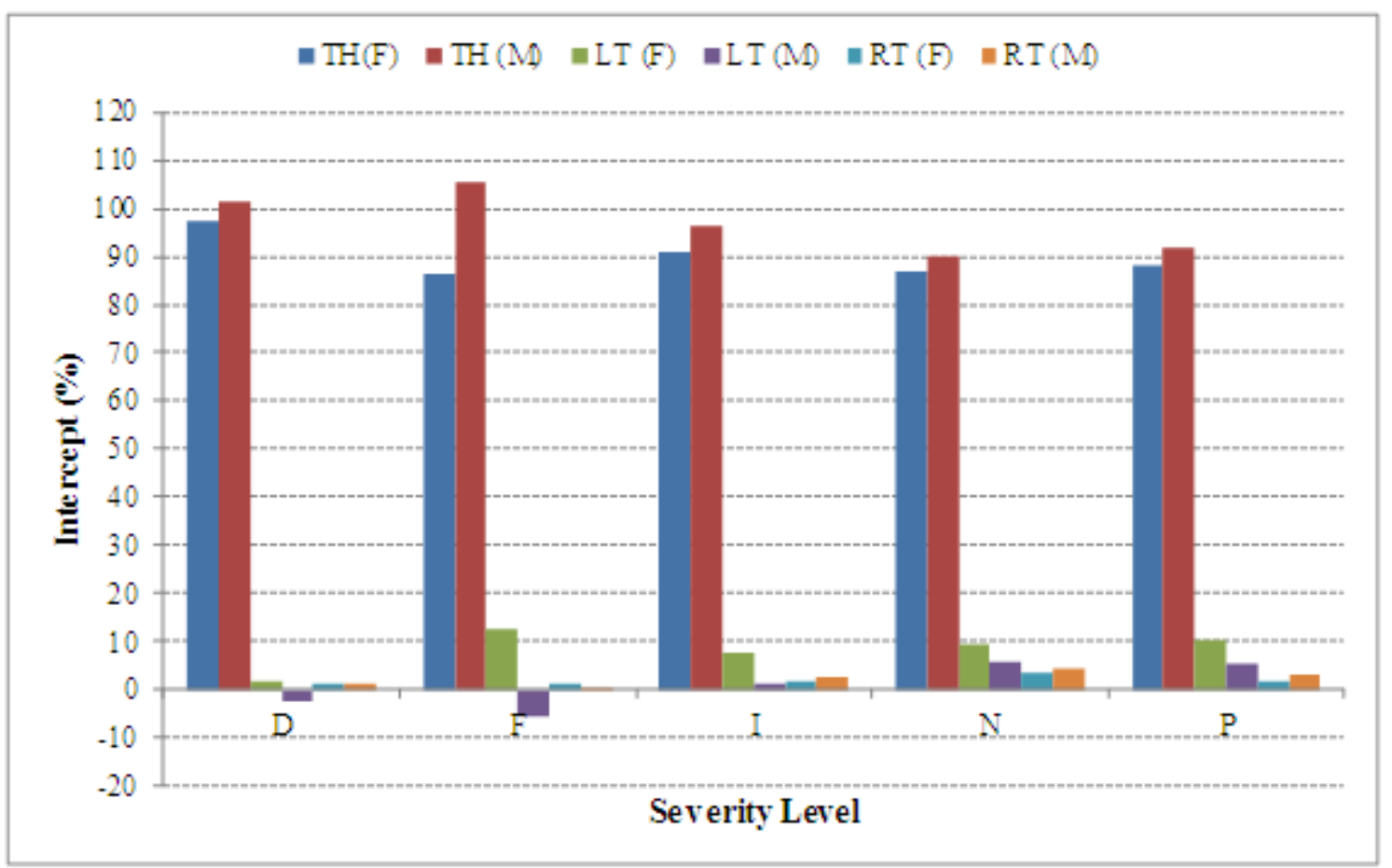

Fig. 1 Intercept at different severity levels. Note: D-Disabled (incapacitating), F-Fatal injury, I-Injury (not incapacitating), $\mathrm{N}-$ Not injured, $\mathrm{P}-$ Possible injury.

are not significant for fatal injury for female.

Statistical estimates for linear model of RT accident are also shown in Table 2. There is no defined trend for RT accident case unlike LT and TH. The slopes and intercepts change in magnitude and sign at different severity levels. The intercepts for males are higher at all severity levels except for fatal injury as shown in Fig. 1. Intercepts are not significant at 
severity levels of disabled and fatal injury for both females and males, possible injury for females. Slopes are not significant for both females and males at severity levels of disabled, fatal injury and possible injury. Slopes for females have higher magnitude than that of males except at fatal injury.

\subsection{Comparison of the Same Gender in Different Age Groups}

The data have been analyzed using different severity levels as replicates for both females and males. Table 3 shows comparison for the same gender in different age groups. The letters in the parenthesis show whether the means are significantly different from each other or not. If they are the same letter, they are not significantly different and vice versa. There is no significant difference for females in age group 1, 2 and 3 for both TH and LT accidents. Age groups 4 and 5 are not significantly different from each other, but significantly different from groups 1, 2 and 3 for both $\mathrm{TH}$ and LT accidents. There is no significant difference for all age groups for RT.

TH in age groups 1 and 2, 3 and 4, 4 and 5 are not significantly different from each other for males. LT in age groups 1 and 2, 2 and 3, 4 and 5 are not significantly different. There is no significant difference for all age groups in the case of RT for males like that of females.

\subsection{Comparison of the Same Age Group for Different Gender}

Comparison has been made for females and males in the same age group for TH, LT and RT accidents. $\mathrm{TH}$ and LT for females and males are not significantly different except for age group 1. RT for females is not significantly different from that of males for all age groups as shown in Table 4.

\subsection{Effect of Light and Weather Condition}

Most of the accidents have taken place during daylight as shown in Fig. 2a. The proportion of the accident increases as age increases and the magnitude is higher for female in all age group during daylight. Dark while there is light on street has the second highest magnitude, but the magnitude decreases as age increases. Since most of the accidents take place during daylight and dark while street lights are on, light condition is not the main cause of accidents for older drivers.

Most of the accidents have taken place when there is no adverse condition. The proportion of the accident increases as age increases and the magnitude is higher for female in all age groups when there is no adverse condition as shown in Fig. 2b. The second highest proportion of accidents has happened when there is rain, mist, or drizzle whereas the magnitude reduces as age increases and higher for females unlike when no adverse conditions. The proportion of accidents during the rest of weather conditions is not significant. Since most of the accidents have taken place when there is no adverse condition, weather condition is not the main problem for older drivers.

\subsection{Effect of Surface Type and Condition}

Effect of surface type is indicated in Fig. 3a. The highest proportion of accidents has taken place on blacktop, followed by concrete. The magnitude is the same on blacktop and concrete surface for almost all age groups. Accidents on the rest of surface types are not significant.

The magnitude of the accident increases with age on dry surface condition as indicated in Fig. 3b whereas accident decreases as age increases on wet surface condition. The magnitude of the accident is higher for female in all age groups on dry surface condition whereas lower for female on wet surface condition. The remaining surface conditions have less contribution. Surface condition is not the main cause of accidents since most of the accidents have taken place on dry surface condition. 
Table 3 Comparison of the same gender in different age groups.

\begin{tabular}{llllllll}
\hline \multirow{2}{*}{ Age group } & \multicolumn{3}{c}{ Female } & & \multicolumn{2}{c}{ Male } \\
\cline { 2 - 4 } & TH & LT & RT & & TH & LT & RT \\
\hline $30-49$ & $82.18^{\mathrm{a}}$ & $15.34^{\mathrm{a}}$ & $2.48^{\mathrm{a}}$ & & $90.52^{\mathrm{a}}$ & $7.12^{\mathrm{a}}$ & $2.36^{\mathrm{a}}$ \\
$50-64$ & $83.96^{\mathrm{a}}$ & $13.74^{\mathrm{a}}$ & $2.30^{\mathrm{a}}$ & & $87.99^{\mathrm{a}}$ & $9.59^{\mathrm{ab}}$ & $2.41^{\mathrm{a}}$ \\
$65-74$ & $80.25^{\mathrm{a}}$ & $16.75^{\mathrm{a}}$ & $3.00^{\mathrm{a}}$ & & $82.88^{\mathrm{b}}$ & $14.49^{\mathrm{b}}$ & $2.64^{\mathrm{a}}$ \\
$75-84$ & $71.86^{\mathrm{b}}$ & $25.12^{\mathrm{b}}$ & $3.02^{\mathrm{a}}$ & & $76.10^{\mathrm{bc}}$ & $21.10^{\mathrm{c}}$ & $2.79^{\mathrm{a}}$ \\
$>85$ & $66.63^{\mathrm{b}}$ & $29.28^{\mathrm{b}}$ & $4.09^{\mathrm{a}}$ & & $70.83^{\mathrm{c}}$ & $26.26^{\mathrm{c}}$ & $2.91^{\mathrm{a}}$ \\
\hline
\end{tabular}

Note: The same letter in the parenthesis indicates that the means are not significantly different for different age group for the same gender and movement type, e.g., there is no significant difference for all age groups in the case of RT for both male and female age groups.

Table 4 Comparison of the same age group of different gender.

\begin{tabular}{|c|c|c|c|c|c|c|c|c|c|}
\hline & \multicolumn{3}{|c|}{ Through } & \multicolumn{3}{|c|}{ Left turn } & \multicolumn{3}{|c|}{ Right turn } \\
\hline Age group & Female & Male & Similar & Female & Male & Similar & Female & Male & Similar \\
\hline $30-49$ & 82.18 & 90.52 & No & 15.34 & 7.12 & No & 2.48 & 2.36 & Yes \\
\hline $50-64$ & 83.96 & 87.99 & Yes & 13.74 & 9.59 & Yes & 2.30 & 2.41 & Yes \\
\hline $65-74$ & 80.25 & 82.88 & Yes & 16.75 & 14.49 & Yes & 3.00 & 2.64 & Yes \\
\hline $75-84$ & 71.86 & 76.10 & Yes & 25.12 & 21.10 & Yes & 3.02 & 2.79 & Yes \\
\hline$>85$ & 66.63 & 70.83 & Yes & 29.28 & 26.26 & Yes & 4.09 & 2.91 & Yes \\
\hline
\end{tabular}

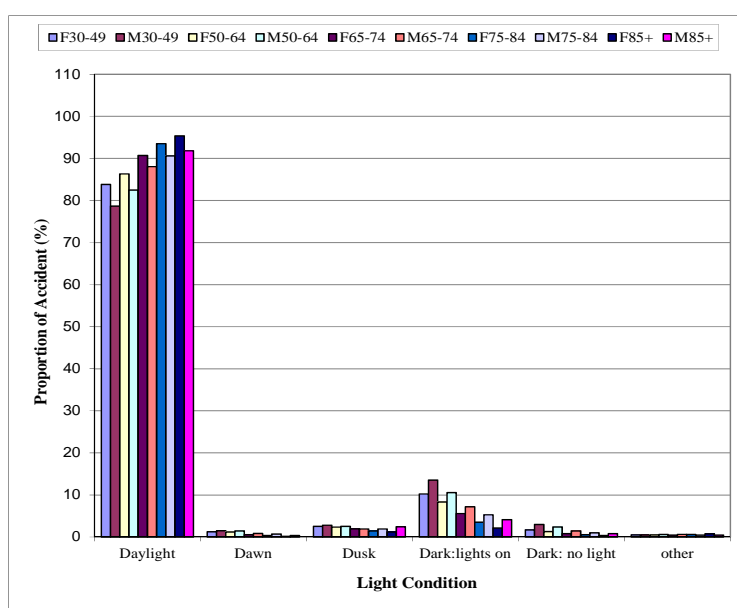

(a) Light condition

Fig. 2 Effect of light and weather condition.

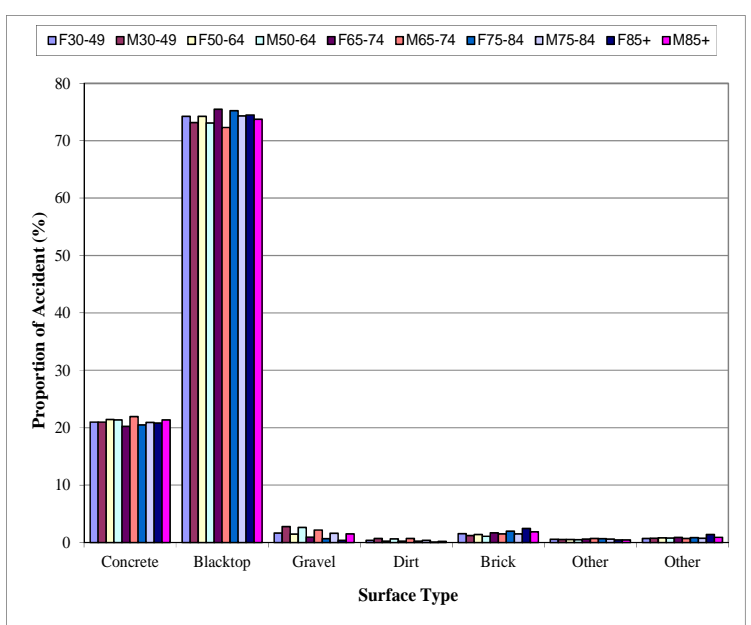

(a) Surface type

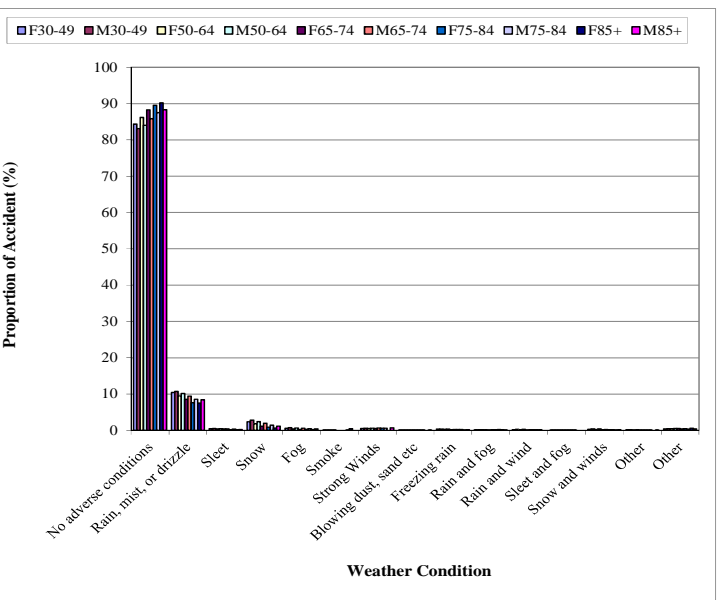

(b) Weather condition

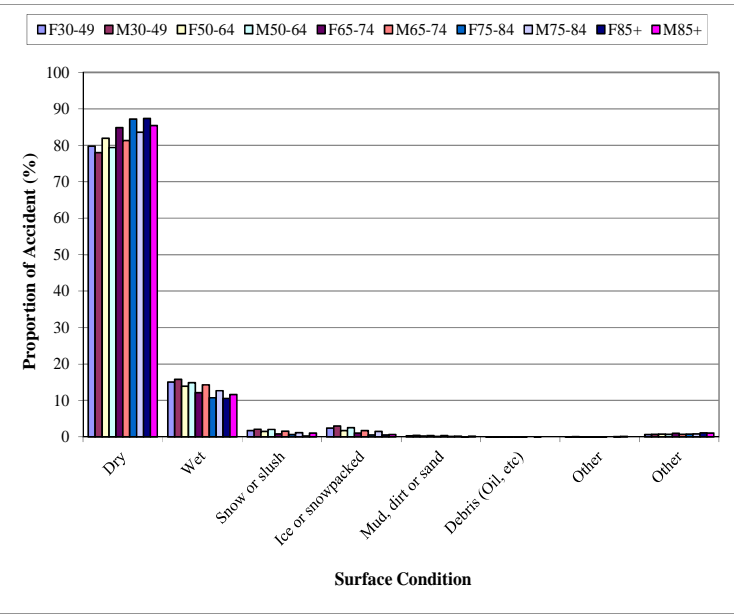

(b) Surface condition

Fig. 3 Effect of surface type and condition. 


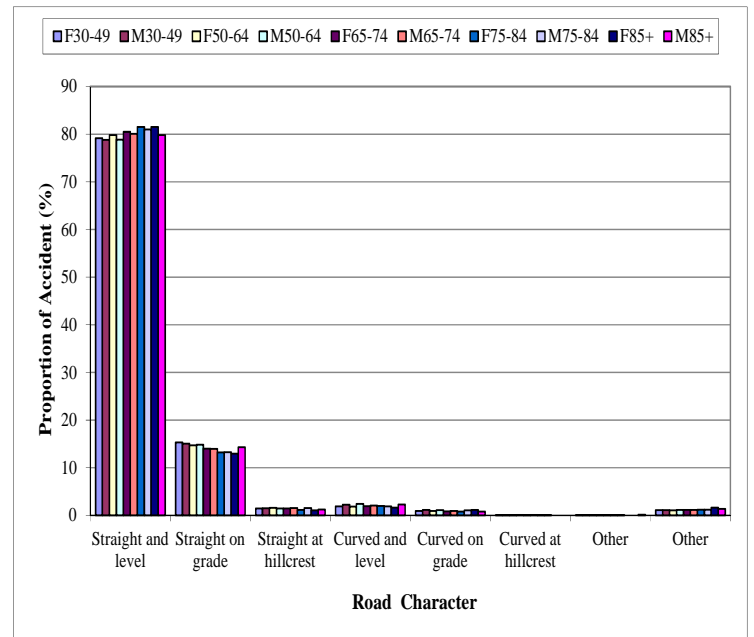

(a) Road character

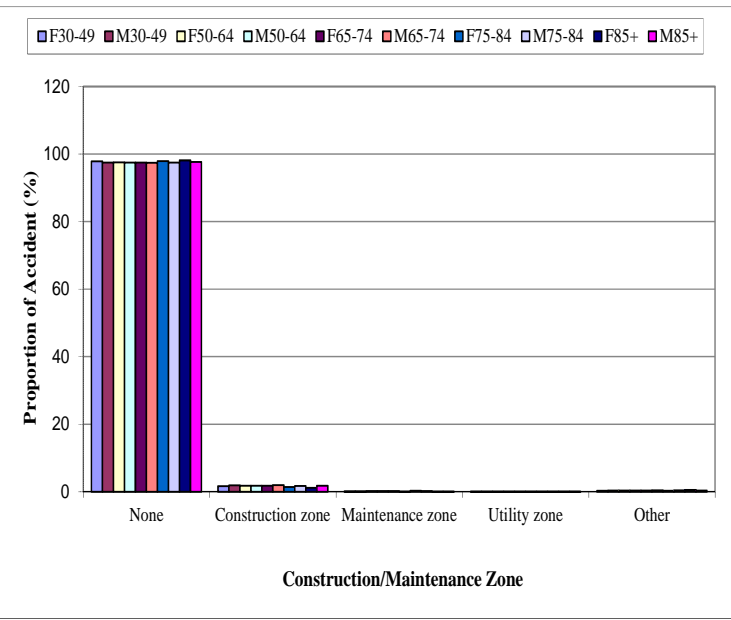

(b) Construction/maintenance zone

Fig. 4 Effect of road character and construction/maintenance zone.

\subsection{Effect of Road Character and \\ Construction/Maintenance Zone}

Most of the accidents have happened on straight and level road as shown in Fig. 4a. The magnitude of accident slightly increases as age increases. The magnitude for female is higher on straight and level road whereas equal on straight on grade except last age group. Accidents on the remaining road characters are insignificant.

Fig. $4 \mathrm{~b}$ shows the effect of construction/maintenance zone. About $98 \%$ of the accidents have taken place on no construction/maintenance zone. The remaining zones cause insignificant accidents.

\section{Conclusions}

Ten years, 1993-2002, accident data have been extracted from Kansas accident report system data base, and analyzed using SAS software for five different age groups. Five severity levels have been considered for both females and males. Based on this study, the following conclusions have been made:

(1) Proportion of older drivers in through lane involved in accident decreases as age increases whereas the proportion of left turn accident increases with age;

(2) Left turn is harder for females in all age groups;
(3) Proportion of right turn accident has no specific trend unlike through and left turn accidents at signalized intersections; and

(4) Most of the accidents have taken place during daylight when there are no adverse conditions on dry surface, straight and level road and blacktop surface type.

\section{References}

[1] R.L. Knoblauch, M. Nitzburg, D. Reinfurt, F. Council, C Zegeer, C. Popkin, Traffic Operations Control for Older Drivers, Research report, Federal Highway Administration, Washington, DC, 1995.

[2] Designing Roadways to Safely Accommodate the Increasingly Mobile Older Driver: A Plan to Allow Older Americans to Maintain Their Independence, The Road Information Program, Washington, DC, 2003.

[3] Improving Public Transit Options for Older Persons, TCRP (transit cooperative research report), 2003, p. 44.

[4] Traffic Safety and Older Americans: Making Roads Safer for Motorists, The Road Information Program, Washington, DC, 2000.

[5] D. Carr, The older adult driver, American Family Physician 61 (2000) 141-148.

[6] M.D. Ladden, Approach to the Evaluation of Older Drivers, http://www.uptodate.com/contents/approach-tothe-evaluation-of-older-drivers (accessed Apr. 17, 2013).

[7] J. Burkhardt, A. McGavock, Tomorrow's Older Drivers: Who? How Many? What Impacts? In Transportation Research Record 1693, National Research Council, Washington, DC, 1999, pp. 62-70.

[8] L. Staplin, K. Lococo, S. Byington, D. Harkey, 
Guidelines and Recommendations to Accommodate Older Drivers and Pedestrians, DIANE Publishing Company, USA, 2003.

[9] J. Yaw, C. Hing, N. Stamatiadis, L. Aultman, Evaluating the impact of passengers on the safety of older drivers, Journal of Safety Research 34 (2003) 343-351.

[10] E.R. Braver, R.E. Trempel, Are older drivers actually at higher risk of involvement in collisions resulting in deaths or nonfatal injuries among their passengers and other road users?, Injury Prevention 10 (2004) 27-32.

[11] A.N. Houser, Older Drivers and Automobile Safety, Research report, AARP Public Policy Institute, 2005.

[12] Addressing the Safety Issues Related to Younger and Older Drivers, U.S. Department of Transportation, NHTSA (National Highway Traffic Safety Administration), 1993.

[13] G. Li, E.R. Braver, L.H. Chen, Exploring the High Death Rates per Vehicle-Mile of Travel in Older Drivers: Fragility Versus Excessive Crash Involvement, Insurance Institute of Highway Safety, Arlington, VA, 2001.

[14] L. Staplin, K.H. Lococo, J. Stewart, L.E. Decina, Safety Mobility for Older Drivers Handbook, Technical report, National Highway Transportation Safety Administration, Washington, DC, 1999.
[15] J. Deacon, Potential Improvement in Roadway Delineation for Older Driver, Transportation in an Ageing Society: Improving Mobility and Safety for Older Persons, Special report 218, Vol. 2, Transportation Research Board, National Research Council, Washington, DC, 1998, pp. 253-269.

[16] I. Bailey, J. Sheedy, Vision Screening for Driver Licensure, Transportation in an Ageing Society: Improving Mobility and Safety for Older Persons, Special report 218, Vol. 2, Transportation Research Board, National Research Council, Washington, DC, 1988, pp. 294-324.

[17] J. Ballard, R. Bishu, P. McCoy, M. Tarawneh, Factors Associated with Driving Performance of Older Drivers, Transportation research record No. 1405, National Research Council, Washington, DC, 1993, pp. 64-71.

[18] At-risk Drivers and Crashes, Older Road User Research Plan, U.S. Department of Transportation, National Highway Traffic Safety Administration, 2001.

[19] American Psychological Association, Guidelines for Psychological Practice with Older Adults, 2003, http://www.apa.org/practice/guidelines/older-adults.pdf (accessed Apr. 17, 2013). 